TUBERCULOSIS

\title{
Coeliac disease and risk of tuberculosis: a population based cohort study
}

\author{
J F Ludvigsson, J Wahlstrom, J Grunewald, A Ekbom, S M Montgomery
}

Thorax 2007;62:23-28. doi: 10.1136/thx.2006.059451

See end of article for authors' affiliations

......................

Correspondence to:

Dr J F Ludvigsson,

Department of Paediatrics,

Örebro University Hospital

Sweden; jonasludvigsson@

yahoo.com

Received 21 January 2006 Accepted 30 May 2006

\begin{abstract}
Background: Coeliac disease (CD) is an autoimmune disease often characterised by malnutrition and linked to a number of complications such as an increased risk of lymphoma, adverse pregnancy outcome, and other autoimmune diseases. Tuberculosis (TB) affects a large proportion of the world population and is more common in individuals with malnutrition. We investigated the risk of TB in 14335 individuals with $C D$ and 69888 matched reference individuals in a general population based cohort study.

Methods: Cox proportional hazards method was used to calculate the risk of subsequent TB in individuals with $C D$. In a separate analysis, the risk of $C D$ in individuals with prior $T B$ was calculated using conditional logistic regression.

Results: $C D$ was associated with an increased risk of subsequent TB (hazard ratio (HR) $3.74,95 \% \mathrm{Cl} 2.14$ to 6.53; $p<0.001$ ). Similar risk estimates were seen when the population was stratified for sex and age at $C D$ diagnosis. Individuals with CD were also at increased risk of TB diagnosed in departments of pulmonary medicine, infectious diseases, paediatrics, or thoracic medicine ( $\mathrm{HR} 4.76,95 \% \mathrm{Cl} 2.23$ to $10.16 ; \mathrm{p}<0.001)$. The odds ratio for CD in individuals with prior TB was 2.50 (95\% Cl 1.75 to $3.55 ; \mathrm{p}<0.001$ ).

Conclusions: $C D$ is associated with TB. This may be due to malabsorption and lack of vitamin $D$ in persons with $C D$. Individuals with $T B$ and gastrointestinal symptoms should be investigated for $C D$.
\end{abstract}

! n coeliac disease $(C D)$ there is chronic inflammation of the small intestine caused by a specific immune response to normally tolerated gluten proteins in wheat, barley, and rye. ${ }^{1}$ The disease has a wide spectrum of clinical manifestations including chronic diarrhoea, abdominal distension and symptoms of intestinal malabsorption, but it can also be asymptomatic. ${ }^{2} \mathrm{CD}$ has been linked to a number of complications including malignancy, ${ }^{3}$ autoimmune disorders, ${ }^{4}$ and adverse pregnancy outcome. ${ }^{5}$

$\mathrm{CD}$ is a common condition in the white ethnic population with a prevalence estimated at $0.5-1 \%{ }^{6}$ Treatment consists of lifelong exclusion of gluten from the diet. Genetics play an important role in $\mathrm{CD}$, with a $75 \%$ concordance rate between monozygotic twins. ${ }^{1}$ There is a very strong linkage to specific human leukocyte antigen (HLA) class II alleles, with approximately $95 \%$ of patients with CD being positive for HLA-DQ2 $\left(\mathrm{DQAl}^{*} 05 / \mathrm{DQBl}^{*} 02\right){ }^{7}$ This particular HLA-DQ molecule associated with this genotype is responsible for presenting gluten peptides to T cells, thus activating gluten-specific CD4+ T cells. ${ }^{8}$ An important factor in the pathogenesis is the intestinal enzyme tissue transglutaminase (tTG) which, by deamidating gluten peptides, enhances their binding to DQ molecules and thereby makes them more potent as T cell stimulators, ${ }^{9}$ and also serves as an autoantigen itself. The detection of anti-tTG antibodies is a highly specific diagnostic test for $\mathrm{CD} .^{10}$ By secreting inflammatory cytokines, the activated $\mathrm{T}$ cells drive the inflammatory response and provide help for B cells making anti-gliadin antibodies.

About one third of the world population is infected with Mycobacterium tuberculosis, but active tuberculosis (TB) occurs in only $5-10 \%$ of exposed individuals. ${ }^{11}$ The disease may occur in any part of the body, but most commonly it is a pulmonary infection. Manifestations of infection range from only a mild infiltration to disease that can be severely destructive, the balance between host defence and bacteria determining the outcome. Following phagocytosis of the mycobacteria by antigen presenting cells such as alveolar macrophages, $\mathrm{T}$ cells of the cell mediated immune response are activated to induce the formation of granulomas (accumulations of macrophages, $\mathrm{T}$ cells, and multinucleated giant cells) which serve to isolate bacteria that cannot be eliminated..$^{12}$ The mycobacteria may be contained in the granuloma, persisting indefinitely as a latent infection, but may also be reactivated later, multiply, and discharged into the airways. $\mathrm{T}$ cells of the Thl type are particularly important in protecting against $M$ tuberculosis infection because they secrete interferon (IFN) $-\gamma$ which enables macrophages to destroy engulfed pathogens more efficiently and to induce granuloma formation. ${ }^{13}$

The first link between CD and TB was suggested by Williams in $1952 .{ }^{14}$ This has since been followed by a number of reports suggesting an association between $\mathrm{CD}$ and $\mathrm{TB} .{ }^{15-19}$ In a British study, six of 76 adult patients with CD reported a history of TB and a further seven had radiological evidence of past TB. ${ }^{18}$ An additional complication is that TB patients with $\mathrm{CD}$ mediated malabsorption may be at risk of resistance to TB drugs because of insufficient uptake of medicine..$^{20}$

In the western world CD affects up to $1 \%$ of all individuals (more in high risk groups), ${ }^{6}$ while more than 14000 new cases of TB were reported to the Centre for Disease Control in the US in 2004. ${ }^{21}$ Despite this, most research on CD and TB is limited to small series of case studies. The evidence of an association between $\mathrm{CD}$ and TB is therefore inconclusive. By linking data from the Swedish national registers, we investigated the risk of TB in a population cohort of some 14000 patients with CD and 70000 age and sex matched controls, and evaluated the risk of $\mathrm{CD}$ in individuals with prior TB.

\section{METHODS}

The Swedish National Board of Health identified all individuals with a hospital discharge diagnosis of CD between 1964 and

Abbreviations: $C D$, coeliac disease; IFN, interferon; SEI, socioeconomic index; TB, tuberculosis 
2003 through the Swedish National Inpatient Register (IPR). The IPR contains individual based data from hospital based discharge diagnoses in selected parts of Sweden since 1964 and has covered all of Sweden since 1987. Every record in the IPR can be identified through a personal identity number, which is a unique number assigned to more than $99.9 \%$ of all Swedish residents and immigrants. ${ }^{22}$

Individuals who received any of the following international classification of disease (ICD) codes between 1964 and 2003 were defined as having CD: ICD-7: 286.00; ICD-8: 269.00, 269.98, ICD-9: 579A; ICD-10: K90.0. For each individual with CD, Statistics Sweden used the national Total Population Register to select up to five reference individuals matched for age, sex, calendar year, and county. The Total Population Register $^{23}$ includes information on area of residence, vital status, and dates of immigration or emigration.

The IPR was then used to identify individuals with TB among the study participants. TB was defined according to the following ICD codes: ICD-7: 001-019; ICD-8: 010-019; ICD-9: 010-018; ICD-10: Al5-A19. The various codes represent different forms of $M$ tuberculosis infection (for example, ICD-9: 010 is primary TB; 011 is lung TB; 012 is other forms of TB in the lungs including pleural TB; 013 is TB in the central nervous system, 014 is TB in the abdomen, 015 is TB in the skeleton or joints; 016 is urogenital TB; 017 is TB in other organs including the skin; and 018 is military $\mathrm{TB}$ ). We specifically recorded individuals with gastrointestinal TB (any of the following ICD codes: ICD-7: 011; ICD-8: 014; ICD-9: 014; ICD-10: A18.3).

We also identified individuals with a hospital discharge diagnosis of sarcoidosis during the 3 year period after the first recorded diagnosis of TB. A diagnosis of sarcoidosis shortly after a TB diagnosis may signal misclassification and a false positive TB diagnosis. Sarcoidosis was defined according to the following ICD codes in the years 1964-2003: ICD-7: 138.00138.10; ICD-8: 135; ICD-9: 135; ICD-10: D86.

Table 1 Characteristics of participants in the main analysis of coeliac disease (CD) and subsequent tuberculosis (TB)

\begin{tabular}{lll}
\hline $\begin{array}{l}\text { Characteristics } \\
\text { Age at first recorded diagnosis }\end{array}$ & $\begin{array}{l}\text { No CD } \\
(\mathbf{n}=69888)\end{array}$ & $\begin{array}{l}\text { CD } \\
\text { ( } \mathbf{n}=14335)\end{array}$ \\
$\begin{array}{l}\text { of CD (years) } \\
\text { 0-15 }\end{array}$ & \\
$\quad-$ & 9368 \\
16+ & - & 4967 \\
Sex & & \\
$\quad$ Men & $28724(41.1)$ & $5909(41.2)$ \\
$\quad$ Women & $41164(58.9)$ & $8426(58.8)$ \\
Calendar period & & \\
1964-1973 & $2.422(3.5)$ & $498(3.5)$ \\
1974-1983 & $19174(27.4)$ & $3920(27.3)$ \\
1984-1993 & $30733(44.0)$ & $6285(43.8)$ \\
1994-2003 & $17559(25.1)$ & $3632(25.3)$ \\
Socioeconomic index* & & \\
I & $7278(10.4)$ & $1504(10.5)$ \\
II & $9251(13.2)$ & $2150(15.0)$ \\
III & $20134(28.8)$ & $5154(36.0)$ \\
Missing data & $33225(47.5)$ & $5527(38.6)$ \\
\hline
\end{tabular}

Data presented as $n(\%)$.

Individuals with more than 1 year of follow up after diagnosis of $C D$ or corresponding date in matched individuals (see text).

*Socioeconomic index: I is the highest category (see text). For reference individuals, the number of individuals who constituted the basis for the Cox regression is given. Data on socioeconomic index were available for another 6527 reference individuals but they were not part of the internally stratified calculations because of missing values on socioeconomic index in the matched individual with $C D$. When the 6527 reference individuals were added to those presented in the table, the proportion of missing values was similar among individuals with $C D$ and those without $C D$.

\section{Exclusion criteria}

The Swedish National Board of Health identified 15533 individuals with CD. Ninety four were excluded because of data irregularities such as death recorded before the first diagnosis of $\mathrm{CD}$. One of the excluded individuals also had a diagnosis of TB. In order to minimise the risk of detection bias, 50 individuals were excluded because TB was diagnosed before study entry and a further 13 were excluded because TB was diagnosed within the first year after the initial CD diagnosis. A further 1040 individuals were excluded because they were followed for less than 1 year, and one individual was excluded because of probable misclassification (the hospital discharge diagnosis consisted partly of a TB ICD code and partly of another ICD code). Similar exclusion criteria were applied to reference individuals. The analyses of the current study were therefore based on 14335 individuals with CD and 69888 reference individuals who had never had $\mathrm{CD}$. Both cohorts were free of TB at the start of the follow up period. Their characteristics are shown in table 1 .

One individual with $\mathrm{TB}$ had received a diagnosis of sarcoidosis during the 3 year period after the first recorded TB diagnosis. All three individuals with a diagnosis of TB where gastrointestinal TB had been recorded as the first recorded TB diagnosis were among those excluded for other reasons. The analyses therefore do not include any individual initially diagnosed with gastrointestinal TB.

A separate analysis of the risk of CD in individuals with prior TB consisted of 15398 individuals with a later diagnosis of CD and 76857 reference individuals without a later diagnosis of CD.

\section{Socioeconomic index (SEI)}

Socioeconomic data were available for a subset of 45471 individuals (table 1) based on classification of occupation from 1968 into three categories where category I denotes a high SEI. ${ }^{24}$ About 6500 of these were children, and they were assigned a socioeconomic code on the basis of the occupation of their mother because divorce is not uncommon in Sweden and children then tend to live with their mothers.

\section{Statistical methods and analyses}

Cox regression was used to calculate hazard ratios (HRs) for subsequent $\mathrm{TB}$ in individuals with $\mathrm{CD}$. The follow up time started 1 year after study entry (date of first recorded diagnosis of $\mathrm{CD}$ and corresponding date in reference individuals) and ended on the date of first discharge diagnosis of $\mathrm{TB}$, date of emigration, death, or the end of the study period (31 December 2003), whichever came first.

The Cox model was internally stratified for age, sex, calendar year, and county, therefore resembling a conditional logistic regression as each individual with $\mathrm{CD}$ was only compared with his/her matched reference controls. This also means that a different baseline hazard function for the risk in the reference group is presumed for each stratum. This is necessary as the follow up begins at different ages/periods for the patients with $\mathrm{CD}$ and the matched comparison population, for whom the follow up begins at the same age/period as the patient with CD in their risk set.

In a separate analysis we stratified for age at first recorded diagnosis of $\mathrm{CD}(\leqslant 15 v \geqslant 16$ years) and sex. In order to increase the specificity of the diagnosis of TB, we specifically looked at individuals who had (1) received their first TB diagnosis in a department of pulmonary medicine, infectious diseases, paediatrics or thoracic medicine; (2) TB listed as the main/first diagnosis (rather than a secondary diagnosis); or (3) no diagnosis of sarcoidosis within 3 years of the first diagnosis 
of TB. Statistical significance was defined as $95 \%$ confidence intervals for HRs not including 1.00.

Conditional logistic regression estimated the risk of CD (the dependent variable) in individuals with prior TB. This analysis was performed in order to see whether or not the association between $\mathrm{CD}$ and TB was independent of sequence-that is, if there was only an association with TB after a diagnosis of CD and not before such diagnosis. The end of the follow up period was defined as the date of first diagnosis of $\mathrm{CD}$ and the same date for the matched controls without CD. Those with 1 year or less between the date of the first TB diagnosis and CD diagnosis and the corresponding date in controls were excluded. Risk estimates are given as odds ratios (OR). Statistics were calculated using SPSS 11.0 (Chicago, IL, USA).

\section{Study power}

The study had an $80 \%$ power to detect a 2.5 -fold increased risk of TB in men and a 2.5-fold increased risk of TB in women. Overall, the study had an $80 \%$ power to detect a 2.0 -fold risk increase for TB at a 5\% significance level; this corresponds to 13 cases of subsequent TB among individuals with $\mathrm{CD}$ (some 14000 ) compared with 35 cases among the referents (some $70000)$

\section{Ethics}

This study was approved by the Research Ethics Committee of the Karolinska Institutet. None of the participants was contacted. Patient information was anonymised prior to the analyses.

\section{RESULTS}

The median age at study entry was 3 years in both individuals with CD and those who had never had a diagnosis of CD (range 0-94 years). About 5000 individuals with CD had been diagnosed in adulthood. Most of the study participants were female (table 1). The median age at the first recorded diagnosis of TB was 66.5 years (range 1-87) in individuals with prior CD. The median time between the first CD diagnosis and the first recorded TB diagnosis was 6.5 years (range 1-26).

Among the 15438 individuals with CD (all individuals with $\mathrm{CD}$ except those with data irregularities) there were 87 cases of TB before or after study entry (0.56\%) compared with 146/ $76908(0.19 \%)$ in the cohort without CD. This is equivalent to a ratio of 1:527 in the general population.

\section{$C D$ and subsequent TB}

TB was more common among patients with CD (HR 3.74, 95\% CI 2.14 to $6.53 ; \mathrm{p}<0.001$, table 2 ). The increased risk was seen in both men and women (table 2). Five of 9368 children later developed TB. This corresponds to a threefold increase in the risk of TB in individuals who had received their first diagnosis of CD during childhood (HR 3.44, 95\% CI 1.09 to 10.85; table 2). Individuals with $\mathrm{CD}$ were also at increased risk of TB diagnosed in departments of pulmonary medicine, infectious diseases, paediatrics, or thoracic medicine (HR 4.76, 95\% CI 2.23 to 10.16; $\mathrm{p}<0.001 ; 31$ positive events). Furthermore, TB listed as the main diagnosis was more common in individuals with $\mathrm{CD}$ than in reference individuals (HR 3.61, 95\% CI 1.92 to 6.76; $\mathrm{p}<0.001 ; 47$ positive events). Only one patient had received a diagnosis of sarcoidosis during the first 3 years after the first inpatient diagnosis of TB; exclusion of this patient from the analyses did not affect the risk estimates (HR 3.87, 95\% CI 2.21 to $6.80 ; \mathrm{p}<0.001)$. Data on SEI were available for a subset of individuals; adjustment for SEI did not affect the risk estimate for TB (crude HR 4.02, 95\% CI 1.57 to 10.28; $\mathrm{p}=0.004$; adjusted HR $4.17,95 \%$ CI 1.60 to $10.86 ; p=0.003 ; 20$ positive events). Including the first year after study entry in the follow up, CD remained a risk factor for subsequent TB (HR 4.77, 95\% CI 2.98 to $7.63 ; \mathrm{p}<0.001 ; 81$ positive events).

\section{$C D$ and prior history of TB}

Conditional logistic regression showed an increased risk of CD in individuals with prior TB (OR 2.50, 95\% CI 1.75 to 3.55; $\mathrm{p}<0.001)$.

\section{DISCUSSION}

The risk of TB in patients with CD was increased 3-4-fold and was also seen when stratified for age and sex. Our study confirms the results of the case-control study by Williams et al ${ }^{18}$ in 1988 and is consistent with the findings of a recent study by a US/Swedish research team. ${ }^{19}$ Unlike the latter study which showed a sixfold increase in death from TB among individuals with $C D$, the current study is not limited to deaths but is based on data from incident cases of TB. Williams et al found a history of TB in six of 76 individuals with $\mathrm{CD} .{ }^{18}$ One of these patients had received a diagnosis of $\mathrm{CD}$ simultaneously with a diagnosis of TB, and in four patients the diagnosis of TB had preceded that of $\mathrm{CD}$. In contrast, we chose to focus on the risk of future TB in a cohort of individuals with diagnosed CD, although we also looked at the risk of $\mathrm{CD}$ in individuals with prior TB.

We excluded the first year after study entry in order to minimise the risk of detection bias. In contrast to the study by Williams et al, ${ }^{18}$ we used a matched approach where each individual with CD was only compared with his/her reference individuals. This means that important potential confounding factors such as age, sex, calendar year, and geographical location within Sweden have little effect on our risk estimates. In our study there was a statistically significant increase in the

\begin{tabular}{|c|c|c|c|c|}
\hline & $\begin{array}{l}\text { No of } \\
\text { participants }\end{array}$ & $\begin{array}{l}\text { No of } \\
\text { events }\end{array}$ & HR $(95 \%$ Cl) & $p$ value \\
\hline No CD & 69888 & 35 & 1.00 & \\
\hline Any CD & 14335 & 24 & $3.74(2.14$ to 6.53$)$ & $<0.001$ \\
\hline \multicolumn{5}{|c|}{ Age at first recorded diagnosis } \\
\hline $0-15$ years & 9368 & 5 & 3.44 (1.09 to 10.85$)$ & 0.035 \\
\hline$\geqslant 16$ years & 4967 & 19 & $3.84(2.03$ to 7.26$)$ & $<0.001$ \\
\hline \multicolumn{5}{|l|}{ Sex } \\
\hline Male & 5909 & 13 & 4.12 (1.89 to 8.97 ) & $<0.001$ \\
\hline Female & 8426 & 11 & $3.38(1.52$ to 7.52$)$ & 0.003 \\
\hline \multicolumn{5}{|c|}{$\begin{array}{l}\text { HR, hazard ratio. } \\
\text { Estimates derived from Cox regression internally stratified for sex, age, year of study entry, and county. } \\
\text { The HR for TB is increased for individuals with CD diagnosed during childhood although the number of events is low (five } \\
\text { individuals with subsequent TB). This is so since each individual with a diagnosis of } C D \text { in childhood is compared only } \\
\text { with his/her five matched reference individuals, also children at study entry. }\end{array}$} \\
\hline
\end{tabular}


risk of TB among both men and women, and in individuals diagnosed with CD in either childhood or adulthood.

In contrast to earlier research, ${ }^{16-18}{ }^{25}$ our study also has the advantage of a very large sample of exposed individuals and some 60 individuals with a later diagnosis of TB. We used national register data of more than 14000 individuals with CD and some 70000 reference individuals. Our population based approach and the public healthcare system in Sweden minimise the risk of biased ascertainment due to socioeconomic inequalities. Although TB is strongly linked to socioeconomic factors, ${ }^{26}$ these factors do not appear to be of importance to a diagnosis of $\mathrm{CD}^{27}$ Socioeconomic data were lacking for a number of individuals; however, such data were available for more than 8800 individuals with CD. Adjustment for SEI did not affect the risk estimate; this is important because SEI among Swedes is strongly linked to smoking habits. ${ }^{28}$

Smoking has repeatedly been shown to increase the risk of $\mathrm{TB}^{29}$ and also to influence the progress and care seeking behaviour at hospital. ${ }^{30}$ The IPR does not contain any smoking data so we could not adjust for smoking. However, smoking is unlikely to induce a positive association between $\mathrm{CD}$ and TB because it has, if any, ${ }^{31}$ a negative ${ }^{32}$ effect on $\mathrm{CD}$ but a positive effect on the risk of TB. This is not consistent with our findings of a positive association between $\mathrm{CD}$ and $\mathrm{TB}$, but we cannot rule out the possibility that inclusion of smoking in our statistical models could have influenced the HRs. We also cannot exclude the possibility that our study suffers from ascertainment bias. Some individuals with gastrointestinal TB may have been screened for $\mathrm{CD}$ and only later received a diagnosis of TB. However, none of the individuals with TB in the prospective study (risk of $\mathrm{TB}$ in individuals with $\mathrm{CD}$ ) had received a diagnosis indicating gastrointestinal TB.

One strength of the current register study is the high specificity of chronic diseases in the IPR, including $\mathrm{CD}^{33}$ and $\mathrm{TB}^{34}$ The high specificity of $\mathrm{CD}$ partly stems from the well established practice in Sweden of performing a small bowel biopsy before confirming a diagnosis of CD. The Swedish IPR has previously also been used to identify cases of TB. ${ }^{34}$ In TB, diagnosis may involve a tuberculin skin test and can be confirmed by radiography and sputum examination. The IPR does not contain any data on the investigations carried out in conjunction with a certain diagnosis, nor does it contain any physical data such as body weight or body mass index. As individual identities are customarily removed from datasets delivered by the Swedish National Board of Health and Welfare before access by researchers, we were unable to verify the diagnoses of $\mathrm{TB}$ in this study against other sources of information. However, in a smaller Swedish study on tumour necrosis factor antagonists and risk of $\mathrm{TB}$, all hospitalised $\mathrm{TB}$ cases (which occurred in the IPR) reflected true TB. ${ }^{34} \mathrm{We}$ increased the specificity of our outcome measure by restricting $\mathrm{TB}$ cases to those diagnosed in departments that often handle cases of suspected TB. This yielded an HR of 4.76. Although there is a risk of misclassification of TB, this should not be a major concern in the current study. Only when misclassification is differential by nature will it affect risk ratios more than marginally. Differential misclassification of CD status is unlikely.

There is a risk that not all individuals with $\mathrm{CD}$ or TB are identified using a hospital based approach. Not all patients with TB are cared for as inpatients, and we do not claim to have complete ascertainment of cases in Sweden from 1964 to 2003. However, admission to hospital for TB may be more common in Sweden than, for example, in the US. ${ }^{34}$ In the study by Askling et al, ${ }^{34} 12$ of 15 patients with TB identified from a source other than the IPR had at some stage been admitted to hospital because of their TB. Such hospital admissions may be for clinical investigation of symptoms and findings such as unexplained inflammation, fever and cough, but may also occur in conjunction with diagnostic procedures such as bronchoscopy. Comparative European data show that the incidence of TB in Sweden in 1998 was lower than in any of the other countries with which it was compared-for example, the incidence in Denmark and Finland was 10-12/100 000, in England and Wales 10-11/100 000, and in Germany 12-13/ $100000 .^{35}$ The lower incidence of $\mathrm{TB}$ and a relatively early decline in TB compared with other European countries may explain the small number of cases of TB in our study.

Since CD is not linked to the SEI, exposure to CD is unlikely to influence care seeking behaviour. However, since CD may differ between ethnic groups, we cannot exclude the possibility that ethnicity may have influenced our results. Although sensitivity may be an issue in this study, the numbers and the statistical power are large. It is important to note that the Swedish IPR also identifies individuals with CD when CD is listed as a secondary diagnosis and the main reason for hospitalisation is for a disease other than CD. Considering that the largest Swedish screening study for CD to date found a prevalence of diagnosed CD in adulthood slightly above $\mathrm{l} /$ $1000,{ }^{36}$ and that the Swedish population is nine million people, we assume that a large proportion of individuals with CD have been identified in this study. It is common for individuals (especially children) to be admitted to hospital while first undergoing small bowel biopsy and then to be transferred to an outpatient setting. The frequent hospitalisation of children for small bowel biopsy partly explains the low median age at diagnosis of CD in the current study. The median age in our cohort is consistent with data from another large Swedish study of $\mathrm{CD} .^{37}$ False negative patients with $\mathrm{CD}$ are unlikely to influence the HRs in this study since they are outnumbered by healthy reference individuals.

There may be several explanations for the association between $\mathrm{CD}$ and TB. As a result of malabsorption of vitamin $\mathrm{D}$ and calcium in patients with $\mathrm{CD},{ }^{38}$ osteomalacia or osteopenia may occur. ${ }^{39}$ This mechanism may operate both before making a diagnosis of CD (when there is intense mucosal inflammation) and after such diagnosis. Individuals with a diagnosis of $\mathrm{CD}$ often have persistent low grade inflammation with affected vitamin status ${ }^{40}$ many years after the introduction of a glutenfree diet. ${ }^{41}$ In addition, the gluten-free diet and products are often low in vitamin $\mathrm{D}_{,}^{42}$ increasing the risk of vitamin $\mathrm{D}$ deficiency in patients with CD. Because of its capacity to activate macrophages, vitamin $\mathrm{D}$ is important for generating an accurate immune response against TB. Vitamin D has been shown to induce the synthesis of nitric oxide in macrophages, thus acting to suppress the growth of $M$ tuberculosis in these cells ${ }^{43}$ Furthermore, vitamin D augments the effect of IFN $\gamma$ in promoting the granulomatous process and promotes the differentiation of monocytes into epitheloid cells and multinucleated giant cells which form prominent parts of granulomas. ${ }^{44}$ Low levels of serum vitamin $\mathrm{D}$ have been found in patients with active TB. ${ }^{45}$ Furthermore, an association has been reported between genetic variants of the vitamin $\mathrm{D}$ receptor and TB infection. ${ }^{46}$ We therefore hypothesise that malnutrition in $\mathrm{CD}$ leads to malabsorption of a number of nutrients including vitamin $\mathrm{D}$ which increases the risk of $\mathrm{TB}$ infection. This underlines the importance of evaluating vitamin D status in patients with $\mathrm{CD}$.

The strongest genetic links to $\mathrm{CD}$ are found within the MHC locus with the well established correlation to HLA-DQ2 $\left(\mathrm{DQAl}^{*} 05 / \mathrm{DQB1}{ }^{*} 02\right) .{ }^{7}$ Associations between $\mathrm{TB}$ and various HLA alleles have been documented, although they are not as strong as in $\mathrm{CD} .^{13}$ To our knowledge, no other strong genetic associations common to CD and TB have been reported. From a 
genetic standpoint, it is of interest that HLA-DQ2 in northern Europeans is often part of the so-called ancestral haplotype 8.1..$^{47}$ This haplotype contains a number of genes including specific alleles of HLA class I and class II molecules, as well as genes for TNF $\alpha$ and complement factors C2 and C4. Since the $\mathrm{C} 2$ molecule, which is polymorphic, is important in the mycobacterial invasion of macrophages, it is possible that a particular C2 allele could promote TB infection in a subgroup of patients.

In some respects the mechanisms of cell mediated immune responses in $\mathrm{CD}$ and $\mathrm{TB}$ seem to be quite different. In $\mathrm{CD}$ the gluten-specific CD4+ T cells driving the pathology are of the Thl type. $^{48}$ In contrast, a robust Thl response is needed for protection against $M$ tuberculosis infection and rare genetic defects in the Thl cytokine pathway (IL-12/IL-23 and IFN $\gamma$ ) increase the susceptibility to TB infection. ${ }^{13}$ Studies of cytokine levels in TB have given divergent results, but some studies have shown an increased Th2 profile. ${ }^{11}$ A polymorphism in the gene for $\mathrm{TNF} \alpha$ has been found to have opposite associations with $\mathrm{CD}$ and TB, since the TNF-308A allele (promoting a high TNF $\alpha$ production) is a susceptibility factor for $\mathrm{CD}^{49}$ and autoimmune disease but a protective factor against TB. ${ }^{50}$

In conclusion, this study shows that $\mathrm{CD}$ is associated with an increased risk of TB. In countries where TB is uncommon, an increase in the relative risk of 3-4 translates into a rather small absolute increase. We hypothesise that the malnutrition associated with $\mathrm{CD}$, particularly vitamin D deficiency, could play an important part in the increased risk of TB. As Peters et $a l^{19}$ found a sixfold increase in the risk of death from TB in individuals with CD and we have reported a 3-4-fold increase in the risk of developing $\mathrm{TB}$, we cannot exclude the possibility that CD may also be a complicating factor in existing cases of $\mathrm{TB}$ and may increase the severity of the disease.

\section{Authors' affiliations}

J F Ludvigsson, Department of Paediatrics, Örebro University Hospital, Sweden

J F Ludvigsson, A Ekbom, S M Montgomery, Clinical Epidemiology Unit, Department of Medicine, Karolinska University Hospital/Institute, Sweden J Wahlstrom, J Grunewald, Division of Respiratory Medicine, Department of Medicine, Karolinska University Hospital/Institute, Sweden

A Ekbom, Harvard Medical School, Boston, Massachusetts, USA

S M Montgomery, Clinical Research Centre, Örebro University Hospital, Sweden

This project was supported by a grant from The Swedish Society of Medicine, the Swedish Research Council, the Sven Jerring Foundation, the Örebro Society of Medicine, the Majblomman Foundation, and the Swedish Coeliac Society. JW and JG were sponsored by the Swedish Heart Lung Foundation, and JG by the Swedish Research Council. JFL was sponsored by the Juhlin Foundation, the Clas Groschinsky Foundation, and was supported by a grant from the Örebro University Hospital while writing this article.

Competing interests: none declared.

\section{REFERENCES}

1 Green PH, Jabri B. Coeliac disease. Lancet 2003;362:383-91.

2 Ludvigsson JF, Ansved P, Falth-Magnusson K, et al. Symptoms and signs have changed in Swedish children with coeliac disease. J Pediatr Gastroenterol Nutr 2004;38:181-6

3 Askling J, Linet M, Gridley G, et al. Cancer incidence in a population-based cohort of individuals hospitalized with celiac disease or dermatitis herpetiformis. Gastroenterology 2002; 123:1428-35

4 Collin P, Reunala T, Pukkala E, et al. Coeliac disease-associated disorders and survival. Gut 1994;35:1215-8.

5 Ludvigsson JF, Montgomery SM, Ekbom A. Celiac disease and risk of adverse fetal outcome: a population-based cohort study. Gastroenterology 2005; 129:454-63.

6 Dube C, Rostom A, Sy R, et al. The prevalence of celiac disease in average-risk and at-risk Western European populations: a systematic review.

Gastroenterology 2005;128(4 Suppl 1):S57-67.
7 James SP. Prototypic disorders of gastrointestinal mucosal immune function: celiac disease and Crohn's disease. J Allergy Clin Immunol 2005;1 15:25-30.

8 Lundin KE, Scott H, Hansen T, et al. Gliadin-specific, HLA-DQ(alpha $1{ }^{*} 0501$, beta $1{ }^{*} 0201$ ) restricted T cells isolated from the small intestinal mucosa of celiac disease patients. J Exp Med 1993;178:187-96.

9 Molberg O, McAdam SN, Korner R, et al. Tissue transglutaminase selectively modifies gliadin peptides that are recognized by gut-derived $T$ cells in celiac disease. Nat Med 1998;4:713-7, 974.

10 American Gastroenterological Association. Medical position statement: celiac sprue. Gastroenterology 2001;120:1522-5.

11 van Crevel R, Ottenhoff TH, van der Meer JW. Innate immunity to Mycobacterium tuberculosis. Clin Microbiol Rev 2002;15:294-309.

12 Raja A. Immunology of tuberculosis. Indian J Med Res 2004;120:213-32.

13 Ottenhoff TH, Verreck FA, Hoeve MA, et al. Control of human host immunity to mycobacteria. Tuberculosis (Edinb) 2005;85:53-64.

14 Williams H. Coeliac syndrome due to tuberculous enteritis. Med J Aust 1952;2:388-9.

15 Hindle W, Creamer B. Significance of a flat small-intestinal mucosa. BMJ 1965:455-8

16 Barry RE, Morris JS, Read AE. A case of small-intestinal mucosal atrophy. Gut 1970;11:743-7.

17 Fung WP, Tan KK, Yu SF, et al. Malabsorption and subtotal villous atrophy secondary to pulmonary and intestinal tuberculosis. Gut 1970;11:212-6.

18 Williams AJ, Asquith P, Stableforth DE. Susceptibility to tuberculosis in patients with coeliac disease. Tubercle 1988;69:267-74

19 Peters U, Askling J, Gridley G, et al. Causes of death in patients with celiac disease in a population-based Swedish cohort. Arch Intern Med 2003; 163:1566-72.

20 Shetty A, McKendrick M. TB and coeliac disease. J Infect 2004;48:109-11.

21 Centre for Disease Control (CDC). Reported tuberculosis in the United States, 2004. Executive commentary, http://www.cdc.gov/nchstp/tb/surv/surv2004/ PDF/ExecutiveCommentary.pdf, 2005.

22 Lunde AS, Lundeborg S, Lettenstrom GS, et al. The person-number systems of Sweden, Norway, Denmark, and Israel. Vital Health Stat 1980;2:1-59.

23 Johannesson I. The total population register of statistics Sweden. New possibilities and better quality. Sweden: Örebro, 2005.

24 Guteland G. Socioekonomisk indelning (SEI). Swedish socioeconomic classification, Reports on Statistical Co-ordination. Stockholm: Statistics Sweden (SCB - Statistiska centralbyrån), 1982.

25 Stevens FM, Connolly CE, Murray JP, et al. Lung cavities in patients with coeliac disease. Digestion 1990;46:72-80.

26 World Health Organization. Addressing poverty in TB control, 2005. http://www.who.int/tb/publications/tb_2005 352 tb_poverty.pdf.

27 Ludvigsson JF. Socio-economic characteristics in children with coeliac disease. Acta Paediatr 2005;94:107-13.

28 Lindstrom M, Moghaddassi M, Bolin K, et al. Social participation, social capita and daily tobacco smoking: a population-based multilevel analysis in Malmo, Sweden. Scand J Public Health 2003:31:444-50.

29 Buskin SE, Gale JL, Weiss NS, et al. Tuberculosis risk factors in adults in King County, Washington, 1988 through 1990. Am J Public Health 1994;84:1750-6.

30 Altet-Gomez MN, Alcaide J, Godoy P, et al. Clinical and epidemiological aspects of smoking and tuberculosis: a study of 13,038 cases. Int J Tuberc Lung Dis 2005;9:430-6

31 Ludvigsson JF, Montgomery SM, Ekbom A. Smoking and celiac disease: a population-based cohort study. Clin Gastroenterol Hepatol 2005;3:869-74

32 Snook JA, Dwyer L, Lee-Elliott $C$, et al. Adult coeliac disease and cigarette smoking. Gut 1996:39:60-2.

33 Smedby KE, Akerman M, Hildebrand $\mathrm{H}$, et al. Malignant lymphomas in coeliac disease: evidence of increased risks for lymphoma types other than enteropathytype T cell lymphoma. Gut 2005;54:54-9.

34 Askling J, Fored CM, Brandt $\mathrm{L}$, et al. Risk and case characteristics of tuberculosis in rheumatoid arthritis associated with fumor necrosis factor antagonists in Sweden. Arthritis Rheum 2005;52:1986-92

35 Broekmans JF, Migliori GB, Rieder HL, et al. European framework for tuberculosis control and elimination in countries with a low incidence. Recommendations of the World Health Organization (WHO), Internationa Union Against Tuberculosis and Lung Disease (IUATLD) and Royal Netherlands Tuberculosis Association (KNCV) Working Group. Eur Respir J 2002;19:765-75

36 Ivarsson A, Persson LA, Juto $P$, et al. High prevalence of undiagnosed coeliac disease in adults: a Swedish population-based study. J Intern Med 1999;245:63-8

37 Ivarsson A, Persson LA, Nystrom L, et al. Epidemic of coeliac disease in Swedish children. Acta Paediatr 2000;89:165-71.

38 Bode S, Gudmand-Hoyer E. Symptoms and haematologic features in consecutive adult coeliac patients. Scand J Gastroenterol 1996;31:54-60.

39 Bernstein CN, Leslie WD. The pathophysiology of bone disease in gastrointestinal disease. Eur J Gastroenterol Hepatol 2003;15:857-64.

40 Hallert C, Grant C, Grehn S, et al. Evidence of poor vitamin status in coeliac patients on a gluten-free diet for 10 years. Aliment Pharmacol Ther 2002; 16:1333-9.

41 Lee SK, Lo W, Memeo L, et al. Duodenal histology in patients with celiac disease after treatment with a gluten-free diet. Gastrointest Endosc 2003;57:187-91.

42 Kupper C. Dietary guidelines and implementation for celiac disease. Gastroenterology 2005;128(4 Suppl 1):S121-7.

43 Rockett KA, Brookes R, Udalova I, et al. 1,25-Dihydroxyvitamin D3 induces nitric oxide synthase and suppresses growth of Mycobacterium tuberculosis in a human macrophage-like cell line. Infect Immun 1998;66:5314-21. 
44 Ohta M, Okabe T, Ozawa K, et al. In vitro formation of macrophageepithelioid cells and multinucleated giant cells by 1 alpha, 25dihydroxyvitamin D3 from human circulating monocytes. Ann NY Acad Sci 1986:465:211-20.

45 Ustianowski A, Shaffer R, Collin S, et al. Prevalence and associations of vitamin $D$ deficiency in foreign-born persons with tuberculosis in London. $J$ Infect 2005;50:432-7.

46 Liu W, Cao WC, Zhang CY, et al. VDR and NRAMP1 gene polymorphisms in susceptibility to pulmonary tuberculosis among the Chinese Han population: a case-control study. Int J Tuberc Lung Dis 2004;8:428-34.
47 Candore G Lio D, Colonna Romano G et al. Pathogenesis of autoimmune diseases associated with 8.1 ancestral haplotype: effect of multiple gene interactions, Autoimmun Rev 2002;1:29-35.

48 Nilsen EM, Lundin KE, Krajci P, et al. Gluten specific, HLA-DQ restricted T cells from coeliac mucosa produce cytokines with Th1 or Th0 profile dominated by interferon gamma. Gut 1995;37:766-76.

49 de la Concha EG, Fernandez-Arquero M, Vigil $\mathrm{P}$, et al. Celiac disease and TNF promoter polymorphisms. Hum Immunol 2000;61:513-7.

50 Correa PA, Gomez LM, Cadena J, et al. Autoimmunity and tuberculosis. Opposite association with TNF polymorphism. J Rheumatol 2005;32:219-24.

\section{LUNG ALERT}

$\beta_{2}$ adrenoceptor polymorphisms (ADRB2 gene) are not strongly associated with asthma incidence or prevalence

$\Delta$ Hall IP, Blakey JD, Al Balushi KA, et al. $\beta 2$-adrenoceptor polymorphisms and asthma from childhood to middle age in the British 1958 birth cohort: a genetic association study. Lancet 2006;368:771-79.

$\mathrm{T}$

he aim of this study was to analyse any potential correlation between $\beta_{2}$ adrenoceptor $(A D R B 2)$ polymorphism and asthma risk and prognosis. The ADRB2 gene contains polymorphic variants with high minor allele frequencies in the white population. The three coding regions, Argl6Gly, Gln27Glu and Thr164Ile, are shown to be functionally relevant. Previous meta analyses looking into the correlation between the genetic polymorphism and asthma risk have produced conflicting results.

In this study people born in the UK during one week in March 1958 were analysed by means of interviews (inquiring after symptoms of asthma, wheezy bronchitis and wheezing) and lung function tests at various ages. Those who had a history of significant wheezy bronchitis during childhood were examined at age 34-35 years by trained nurses and spirometry was performed. People who were still in contact with the study at age $42-45$ years had DNA extraction for genotyping, measurement of immunoglobulin E levels and spirometry. A separate group of 41 individuals with severe asthma was recruited for specific genotyping.

Half of the cohort of 8018 individuals had some history of wheezing by the age of 42 . No significant association of any one single nucleotide polymorphism was seen with lifetime prevalence or age of asthma onset. However, there was a small correlation between persistence of asthmatic symptoms from childhood to middle age and Argl6Gly and Gln27Glu gene polymorphism. Childhood wheezers who were homozygotes for the Argl6-Gln27 haplotype had five or more wheezing episodes in the past year at the age 42. The authors also did a further meta analysis including the results of previous studies and this did not show a significant correlation between gene polymorphism and prevalence or severity of asthma.

The results of this genetic association study in a British population do not confirm a significant correlation between $\beta_{2}$ adrenoceptor polymorphisms and asthma risk or prevalence. However, any potential correlation between such genetic findings and the prognosis of childhood wheezing needs to be determined with more specifically designed studies.

M Pagaria

Intermediate Trainee Intensive Care, Gloucestershire Royal Hospital, Gloucester, UK; dr_pagaria@yahoo.co.uk 